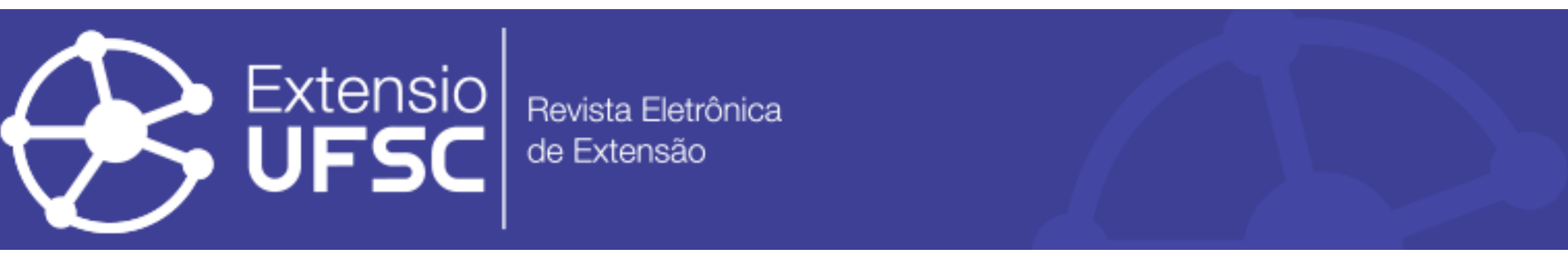

\title{
GÊNERO, SAÚDE E ENFERMAGEM: RESSIGNIFICANDO O SUJEITO
}

\author{
Erika Carla de Sousa Dias \\ Universidade do Estado do Rio Grande do Norte \\ erika.pb2013@hotmail.com \\ Rafael Tavares Silveira Silva \\ Universidade do Estado do Rio Grande do Norte \\ rtssrafa@yahoo.com.br \\ Ellany Gurgel Cosme do Nascimento \\ Universidade do Estado do Rio Grande do Norte \\ ellanygurgel@hotmail.com
}

\begin{abstract}
Resumo
Pretende-se, através desse Relato de Experiência, compartilhar a vivência de discentes do $3^{\circ}$ período do Curso de Enfermagem da Universidade Estadual do Rio Grande do Norte (UERN) na execução da atividade de extensão intitulada "10 Seminário Gênero, Saúde e Enfermagem: ressignificando o sujeito", o qual ocorreu em maio de 2016 na Casa da Cultura na cidade de Pau dos Ferros/RN, com o objetivo de estimular, na comunidade local, discussões sobre gênero na perspectiva de desconstruir preconceitos e promover empoderamento. Contou com a participação da população da referida cidade e nas mesas de discussão, de representantes dos movimentos LGBT e feminista, assim como de profissionais de saúde, pesquisadores das áreas de saúde e social. O evento foi considerado valoroso, porque possibilitou aos estudantes o protagonismo na organização e exposição de trabalhos acadêmicos sobre a temática proposta, aproximando-os da realidade da comunidade numa troca de experiências e saberes, bem como oportunizou a sociedade local um espaço para diálogo e promoção de tolerância e respeito, na perspectiva de uma sociedade mais justa e igualitária.
\end{abstract}

Palavras-Chaves: Gênero e Saúde. Educação. Relações Comunidade-Instituição. Minorias Sexuais e de Gênero. Feminismo.

\section{GENDER, HEALTH AND NURSING: RESSIGNIFICATING THE PEOPLE}

\begin{abstract}
It is intended, through this Report of Experience, to share the experience of students of the third period of the Nursing Course of the Universidade Estadual do Rio Grande do Norte (UERN) in the execution of the extension activity entitled “" $1^{\circ}$ Seminário Gênero, Saúde e Enfermagem: ressignificando o sujeito" ", which took place in May 2016 at the Casa da Cultura in the city of Pau dos Ferros/RN, with the aim of stimulating discussions with the local community about gender in order to deconstruct prejudices and promote empowerment. There was participation of the local population and, at the discussion tables, LGBT and feminist movements representative, as well as health professionals and health and social researchers. The event was considered valuable because it enabled students the protagonism in the organization and exhibition of academic works on the proposed theme, bringing them closer to the reality of the community in an exchange of experiences and knowledge, as well as giving local society a space for dialogue and promotion of tolerance and respect, in the perspective of a more just and egalitarian society.
\end{abstract}

Key Words: Gender and Health. Education. Community-Institutional Relations. Sexual and Gender Minorities. Feminism.

\section{Resumen}

\section{GÉNERO, SALUD Y ENFERMERÍA: RESSIGNIFICANDO EL SUJETO}

Se pretende, a través de ese Relato de Experiencia, compartir la vivencia de discentes del $3^{\circ}$ período del Curso de Enfermería de la Universidade Estadual do Rio Grande do Norte (UERN) en la ejecución de la actividad de extensión titulada " $1{ }^{\circ}$ Seminário Gênero, Saúde e Enfermagem: ressignificando o sujeito”, el cual ocurrió en mayo de 2016 en la Casa da Cultura en la ciudad de Pau dos Ferros / RN, con el objetivo de estimular, en la comunidad local, discusiones sobre género en la perspectiva de deconstruir prejuicios y promover empoderamiento. Se contó con la participación de la población de dicha ciudad y en las mesas de discusión, de representantes de los movimientos LGBT y feminista, así como de profesionales de salud, investigadores de las áreas de salud y social. El evento fue considerado valeroso porque permitió a los estudiantes el protagonismo en la organización y exposición de trabajos académicos sobre la temática propuesta, acercándolos a la realidad de la comunidad en un intercambio de experiencias y saberes, así como oportunizó a la sociedad local un espacio para el diálogo y la promoción de tolerancia y respeto, en la perspectiva de una sociedad más justa e igualitaria.

Palabras Claves: Género y Salud. Educación. Relaciones Comunidad-Institución. Minorías Sexuales y de Género. Feminismo. 
Gênero, saúde e enfermagem: ressignificando o sujeito

\section{INTRODUÇÃO}

A extensão teve início no século XX na Inglaterra, cujo objetivo era nortear novos caminhos para a sociedade e criar a educação continuada. Atualmente, é vista como uma estratégia a ser utilizada pela Universidade para o cumprimento do seu compromisso social. A elaboração do significado de extensão tem como propósito induzir a Universidade e a comunidade em um propósito comum, possibilitando vantagens e conquistando conhecimentos, para ambas. Assim, desempenha função relevante em relação aos subsídios que pode proporcionar para à comunidade. Faz-se necessário, por parte da Universidade, expor pareceres de que a extensão possui vinculado a sociedade em geral. Vivenciar na prática as teorias estudadas em sala de aula é desenvolvê-la fora dela (RODRIGUES, 2013).

Dentre os diversos locais de construção do conhecimento, a Universidade está em um lugar privilegiado de desenvolvimento e de contato humano, científico-tecnológico e social. Possui como estrutura central a formação de profissionais-cidadãos, ou seja, preocupados e engajados com a evolução da sociedade local e global (PIVETTA et al, 2010).

Através das atividades de extensão, portanto, é possível criar um espaço no qual a academia se aproxima dos problemas e das reais necessidades da população. Nesse contexto, os movimentos sociais, constituídos por parte da sociedade civil e organizada, encontram possibilidades de escuta qualificada e parcerias para suas reivindicações de ações e direitos, que muitas vezes são marginalizadas. Exemplo disso, o Movimento LGBT, constituído por pessoas lésbicas, gays, bissexuais, travestis, transexuais e queers, que desde a década de 1980 tem se unido pela luta da liberdade sexual e igualdade de direitos e nas últimas décadas têm se aproximado das discussões acadêmicas. (FERREIRA, 2015; MOLINA, 2011).

Atualmente, vê-se a evolução do Movimento LGBT e da evidência das indagações que estão relacionadas às questões da homossexualidade e das inúmeras formas de referência e identidades de gênero no Brasil. Porém, mesmo havendo progressos, principalmente representados pela atuação de programas governamentais e por meio da crescente abertura do debate público, é importante destacar que ainda existem desafios (CARRARA, 2012).

No contexto dos serviços de saúde e educacionais, o preconceito e a discriminação que enfrenta a população LGBT, não são diferentes (CERQUEIRA-SANTOS et al., 2010). Assim, faz-se necessário divulgar e discutir as questões que envolvem as lutas para aceitação do 'gênero' em nossa sociedade. Por isso, a responsabilidade social da Universidade de extrapolar seus muros e se envolver com a comunidade, para que se possa garantir o respeito ao ser humano. 
Gênero, saúde e enfermagem: ressignificando o sujeito

Partindo dessa premissa, surgiu a proposta do "10 Seminário Gênero, Saúde e Enfermagem: Ressignificando o Sujeito", o qual tinha o intuito de estimular as discussões acerca do respeito ao grupo LGBT e às mulheres, na perspectiva de compartilhar informações e produzir empoderamento. Portanto, pretende-se através desse artigo, compartilhar as experiências vivenciadas pelos organizadores na execução do referido seminário.

\section{MATERIAIS E MÉTODOS}

Trata-se de um relato de experiência dos organizadores do "1 Seminário Gênero, Saúde e Enfermagem: Ressignificando o Sujeito”, vivenciada durante o período de seu planejamento e execução. Tal evento foi desenvolvido como uma atividade de extensão, vinculado ao Curso de Graduação em Enfermagem da Universidade do Estado do Rio Grande do Norte (UERN) - Campus Avançado Professora Maria Eliza de Albuquerque Maia (CAMEAM), o qual teve como público discentes do Curso de Graduação em Enfermagem, grupos de jovens do Município de Pau dos Ferros ligados às Secretarias de Ação Social e de Cultura, população em geral, e comunidade LGBT.

O "1 Seminário Gênero, Saúde e Enfermagem: Ressignificando o Sujeito" nasceu da inquietação dos discentes do terceiro período do Curso de Graduação em Enfermagem da UERN/CAMEAM quanto ao preconceito e discriminação que existem contra a população LGBT e mulheres. Na perspectiva de não compactuar com esse contexto, os acadêmicos sentiram a necessidade de fazer algo que pudesse de alguma forma combater tais males em seu contexto regional. Então, a união dos componentes curriculares obrigatórios "Gênero, saúde e enfermagem” e "Processo investigar em enfermagem", ambos oferecidos no mesmo período, numa proposta de atividade interdisciplinar foi sugerida a atividade de extensão, que foi aprovada pelo colegiado do curso e apoiada pelas Secretarias Municipais de Ação Social e Cultura do Município de Pau dos Ferros/RN.

O evento foi organizado pelos acadêmicos, sob a orientação e supervisão da professora e do professor dos componentes supracitados. O planejamento aconteceu durante as aulas de ambos os componentes durante os meses de março, abril e maio de 2016. E o evento ocorreu na Casa da Cultura na Cidade de Pau dos Ferros/RN no dia 20 de maio de 2016 das oito ao meio dia.

Durante a execução do seminário houveram mesas de discussões com os temas "O olhar do Movimento Feminista sobre a violência de gênero contra a mulher nos espaços escolares" e "O olhar do Movimento LGBT sobre a violência de gênero contra a população LGBT nos espaços escolares”, com a representação do Movimento LGBT, Grupo Feminista, profissionais de saúde e pesquisadores das áreas de saúde e social. Assim como também apresentação de banner pelos discentes, os quais 
Gênero, saúde e enfermagem: ressignificando o sujeito

abordavam as temáticas: Feminino e masculino: o ser homem e o ser mulher na perspectiva de análise do gênero; Entre anjos e demônios: os momentos históricos que compõem a enfermagem; Quando a prostituta se santifica: gênero e sexualidade na enfermagem; Criando novo estereótipo: a inserção masculina na enfermagem; $O$ processo saúde-doença de homens e mulheres: a questão da determinação social; As práticas de atenção à saúde da mulher no Brasil; E Onde ficam os homens? Política Nacional de Saúde dos Homens; Nem rosa nem azul: lilás como representativo das minorias LGBT.

\section{RESULTADOS E ANÁLISES}

Em 2013 a Secretaria de Direitos Humanos ligada ao Ministério de Direitos Humanos do Brasil, publicou um relatório sobre a violência homofóbica, o qual apontou quase 10 mil tipos de violações dos direitos humanos de pessoas LGBT, envolvendo 4.851 vítimas (BRASIL, 2013). Esse contexto de violência no Brasil, também foi observado pela ONG Internacional Transgender Europe, a qual aponta que em 2017, tal país é a nação que mais morrem travestis e transexuais por assassinato (FERDOKO; BERREDO, 2017).

Não só a população LGBT sofre com preconceito e discriminação no Brasil, mas também as mulheres, independendo de suas orientações sexuais. O Mapa da Violência de 2015 aponta que em 2013 foram assassinadas 4.762 mulheres, ou seja, algo em torno de 13 homicídios por dia. Tais dados colocam o país na $5^{a}$ colocação entre aqueles que tem maior número de feminicídio (WAISELFISZ, 2015).

A violência sofrida tanto por LGBT quanto por mulheres no Brasil, foram temas discutidos durante as aulas do componente curricular "Gênero, saúde e enfermagem” da UERN/CAMEAM. Tal realidade causou inquietação nos discentes, fazendo surgir a ideia do "1 Seminário Gênero, Saúde e Enfermagem: Ressignificando o Sujeito" como uma forma de combater tal mal e não se sentir impotente.

Então, no decorrer dos meses de março, abril e maio, as aulas dos dois componentes curriculares supracitados foram utilizadas para também planejar o seminário. As funções de cada acadêmico foram determinadas segundo habilidades, voluntariamente e democraticamente nas comissões: científica; secretaria e cerimonial; divulgação; patrocínio; infraestrutura. Concomitante, os discentes estudaram a temática e realizaram pesquisas bibliográficas, as quais foram compartilhadas em sala de aula e depois subsidiaram a construção de banners que foram apresentados no intervalo das mesas de discussão do seminário para o público que lá estava.

O protagonismo dos discentes na elaboração e apresentação dos banners foi importante para eles, pois se trata de uma contribuição positiva no seu processo formativo em Enfermagem, visto que 
nessa oportunidade eles puderam exercitar e desenvolver uma das competências e habilidades inerente a profissão, a comunicação, seja ela verbal ou escrita (BRASIL, 2001). É importante mencionar que a formação em Enfermagem da UERN/CAMEAM não é só em bacharelado, mas também em licenciatura, o que requer dos acadêmicos mais aptidões para o processo de ensino e aprendizado. Da mesma maneira que também possibilitou a aproximação com a comunidade e a responsabilidade em se preparar para debater temas sociais.

A construção do seminário também viabilizou aos discentes a experiência de planejar uma atividade de abrangência local para além dos muros da Universidade, estimulando o trabalho coletivo, o diálogo entre os pares e o planejamento. Possibilidade essa que não se encontra na sala de aula e em nenhum componente curricular.

O evento, pensado a partir de tópicos problematizadores, também foi positivo para a comunidade, pois o público participante demostrou aceitação, ouvindo as discussões realizadas, mas também participando do diálogo com depoimentos e explanando experiências vividas de preconceito e discriminação assim como compartilhando opiniões, tornando a atividade valiosa e apreciada por todos que ali estavam.

A aceitação do público participante do seminário foi atestada por um questionário, o qual foi elaborado pelos discentes e professores envolvidos. Ele continha as seguintes questões: Como você avalia o "10 Seminário gênero saúde e enfermagem: ressignificando o sujeito?"; "Esse seminário trouxe alguma contribuição para você?”; "Como você avalia a apresentação dos banners?”; "Os palestrantes conseguiram contemplar a mensagem abordada pelo seminário?”; "O que você acha sobre o tema abordado pelo seminário?”; "Como você avalia a estrutura do local?”; “A palestra conseguiu descontruir algum preconceito que você tinha em relação aos temas abordados?"; "Se houvesse outro seminário com um tema relacionado a esse você participaria?"; Seminários como esse ajudam a população a entenderem importância da discussão de gênero da sociedade?”

A partir do questionário, percebeu-se que dos 56 participantes que o responderam, todos fizeram uma avaliação positiva, pois consideraram o seminário excelente, assim como o local de realização, como também a contribuição que o mesmo trouxe para a comunidade e o quanto ele ajudou a população para um maior esclarecimento e entendimento sobre a discussão de gênero por meio dos trabalhos apresentados e da partilha de conhecimentos.

Os participantes também manifestaram o desejo de participar de outros eventos relacionados a gênero ou temáticas similares: Feminismo e politicas LGBT; Informação; Respeito e ações representativas sobre outras orientações sexuais além de homossexual, heterossexual e bissexual; Prostituição; Feminismo; Surdo e mudo; Ações contra as práticas racistas; Assistência Social; Subtemas 
com conceitos acerca do tema; Respeito no geral; Violência contra a mulher; Surdez; Saúde sexual; Sexualismo; Serviço social; Gênero e sexualidade LGBT; Racismo; Adoção em homoparentais; Violência; Desconstrução de uma cultura de gênero e sexualidade LGBTS; Descriminação social; Direitos sociais e políticas de minoria; Igualdade na saúde e direito de todos; Cotas para as minorias e a dificuldade da entrada na universidade; Violência sexual; Estrupo; Assistência de saúde ao grupo LGBT. As temáticas sugeridas partiram do pressuposto de que a sociedade não tem um conhecimento científico acerca da política LGBT e suas dimensões.

O "1 Seminário Gênero, Saúde e Enfermagem: Ressignificando o Sujeito”, destarte, alcançou os objetivos propostos, pois conseguiu estimular na comunidade a discussão sobre gênero em prol do combate do preconceito e a discriminação contra mulheres e LGBT, incentivando a tolerância e o respeito. Em vista disso, acredita-se que tal evento foi um primeiro passo para que as pessoas que ali estavam tenham desmistificado seus próprios preconceitos, ou mesmo, se empoderaram para enfrentalos.

Seminários como este são fundamentais na atualidade, afinal a dimensão de gênero tem sido incorporada, acertadamente, cada vez com maior notoriedade nas políticas públicas de saúde e de educação (FERRAZ; KRAICZYK, 2010; VIANNA, 2015). Discutir tal temática, portanto contribui para se pensar o gênero e a diversidade sexual como aspectos inerentes da organização social, assim como fortalece a luta pela ampliação dos direitos para essas pessoas que historicamente sofrem com a falta de isonomia (VIANNA, 2015).

Nesse sentido, é de fundamental importância a realização de eventos como atividade de extensão que se aproxime das pessoas com objetivo de fazê-las conhecer e compreender a necessidade do convívio harmonioso em sociedade, pois a partir de situações como estas, a Universidade está efetivamente formando seres pensantes e críticos, capazes de disseminaram conhecimentos e atuarem como agentes de transformação no meio que estão inseridos. Conforme Serrano (2013), o processo de ensino e extensão ultrapassa as paredes da sala da aula, perpassando o ambiente fechado da Universidade, para que aconteça troca de conhecimento oriundo do meio social. Assim, o conteúdo ganha um novo sentido, permitindo a construção de conhecimentos.

A Universidade na sua dimensão da responsabilidade social universitária, através do "1" Seminário Gênero, Saúde e Enfermagem: Ressignificando o Sujeito”, cumpre, portanto, seu papel com os seus discentes, pois o evento foi um canal para aperfeiçoamento de mentes humanas proativas capazes de contribuir para construção de um coletivo socialmente responsável, cidadão e igualitário. E, portanto, dessa forma, também contribuiu para o desenvolvimento da comunidade (RIBEIRO; MAGALHÃES, 2014). 
Gênero, saúde e enfermagem: ressignificando o sujeito

\section{CONSIDERAÇÕES FINAIS}

Diante de uma realidade de preconceito e discriminação que atingem LBGT e mulheres, o "1" Seminário Gênero, Saúde e Enfermagem: Ressignificando o Sujeito" proposto como uma forma de combate, alcançou seus objetivos, promovendo o protagonismo dos discentes na apresentação dos banners, assim como no planejamento da ação de extensão, dessa forma, atendendo aos preceitos das atividades de extensão, que é aproximar os estudantes da realidade e da comunidade numa troca de experiências e saberes. Ainda, oportunizou à comunidade, espaço para discussão e exposição de opiniões na perspectiva de desconstruir preconceitos, promover empoderamento, tolerância e respeito. Bem como contribuiu para o desenvolvimento da sociedade local quanto a isonomia e a cidadania.

Avalia-se, portanto, o evento positivamente, pois foi possível atingir o público alvo, conforme planejado, estimulou-se discussões importantes e articulou-se o ensino, pesquisa e extensão, num só momento. Além do mais, a avaliação dos participantes foi positiva, o que resultou no estabelecimento da meta de realização anual do evento.

Com tudo isso, espera-se que outras experiências como essa sejam realizadas em outras Universidades, outros cursos de enfermagem, de saúde e também nos cursos de educação, pois se trata de uma oportunidade ímpar para construção de um Brasil mais justo e igualitário.

\section{REFERÊNCIAS}

BRASIL. Secretaria de Direitos Humanos. Relatório sobre violência homofóbica no Brasil: ano de 2012. Brasília: Secretaria de Direitos Humanos, 2013.

BRASIL. Conselho Nacional de Educação. Câmara de Educação Superior. Resolução CNE/CES no 3, de 7 de novembro de 2001. Institui Diretrizes Curriculares Nacionais do curso de graduação em enfermagem. Brasília, 2011. Disponível em: < http://portal.mec.gov.br/cne/arquivos/pdf/CES03.pdf>. Acesso em: 02 jun. 2018.

CARRARA, Sérgio. Políticas e direitos sexuais no Brasil contemporâneo. Bagoas-Estudos gays: gêneros e sexualidades, v. 4, n. 05, 2012.

CERQUEIRA-SANTOS, Elder et al.. Percepção de Usuários Gays, Lésbicas, Bissexuais e Transgêneros, Transexuais e Travestis do Sistema Único de Saúde. Revista Interamericana de Psicología/Interamerican Journal of Psychology, v. 44, n. 2, p. 236-245, 2010.

FEDORKO, Boglarka; BERREDO, Lukas. O círculo vicioso da violência: pessoas trans e gênerodiversas, migração e trabalho sexual. Série de publicações TvT, v. 19, out. 2017. Disponível em: < https://transrespect.org/wp-content/uploads/2018/01/TvT-PS-Vol19-2017.pdf>. Aceso em jun. 2018. 
FERRAZ, Dulce; KRAICZYK, Juny. Gênero e Políticas Públicas de Saúde - construindo respostas para o enfrentamento das desigualdades no âmbito do SUS. Revista de Psicologia da UNESP, v. 9, n. 1, 2010. Disponível em: <http://seer.assis.unesp.br/index.php/psicologia/article/view/428>. Acesso em: 02 jun. 2018.

FERREIRA, Amanda Cristina De Souza. GÊNERO E RELAÇÕES DE OPRESSÃO: breves reflexões. Revista Gênero \& Direito, v. 4, n. 1, 2015.

MOLINA, Luana Pagano Peres. A homossexualidade e a historiografia e trajetória do movimento homossexual. Antíteses, v. 4, n. 8, p. 949-962, jul./dez. 2011

PIVETTA, Hedioneia MariaFoletto et al. Ensino, pesquisa e extensão universitária: em busca de uma integração efetiva. Linhas Críticas, v. 16, n. 31, 2010.

RIBEIRO, Raimunda da Cunha; MAGALHÃES, António M. Política de responsabilidade social na universidade: conceitos e desafios. Educação, Sociedade \& Culturas, n. 42, p. 133-156, 2014. Disponível em: < https://repositorio-aberto.up.pt/bitstream/10216/77917/2/97463.pdf>. Acesso em: 02 jun. 2018.

RODRIGUES, Andréia Lilian Lima et al. Contribuições da extensão universitária na sociedade. Caderno de Graduação-Ciências Humanas e Sociais-UNIT, v. 1, n. 2, p. 141-148, 2013.

SERRANO, Rossana Maria Souto Maior. Conceitos de extensão universitária: um diálogo com Paulo Freire. Grupo de Pesquisa em Extensão Popular.v. 13, n. 08, 2013.

VIANNA, Cláudia Pereira. O movimento LGBT e as políticas de educação de gênero e diversidade sexual: perdas, ganhos e desafios. Educação e Pesquisa, v. 41, n. 3, p. 791-806, 2015. Disponível em: < http://www.redalyc.org/pdf/298/29841640014.pdf >. Acesso em: 02 jun. 2018.

WAISELFISZ, Julio Jacobo. Mapa da violência 2015: homicídio de mulheres no Brasil. Brasília: FLASCO-Brasil, $2015 . \quad$ Disponível em: < https://www.mapadaviolencia.org.br/pdf2015/MapaViolencia_2015_mulheres.pdf>. Acesso em 02 jun. 2018.

Recebido em: 28/08/2017

Aceito em: 18/06/2018 